\title{
EVALUATION OF RHBMP-2/COLLAGEN/TCP-HA BONE GRAFT WITH AND WITHOUT BONE MARROW CELLS IN THE CANINE FEMORAL MULTI DEFECT MODEL
}

\author{
V. Luangphakdy ${ }^{1}$, K. Shinohara ${ }^{1}$, H. Pan $^{1}$, C. Boehm ${ }^{1}$, A. Samaranska ${ }^{2}$ and G.F. Muschler ${ }^{1, *}$ \\ ${ }^{1}$ Department of Biomedical Engineering, Lerner Research Institute, Cleveland Clinic, Cleveland, OH, USA \\ ${ }^{2}$ Medtronic Spinal and Biologics Division, Memphis, TN, USA
}

\begin{abstract}
Recombinant human bone morphogenetic protein-2, when applied to an absorbable type 1 bovine collagen sponge (rhBMP-2/ACS) is an effective therapy in many bone grafting settings. Bone marrow aspirate (BMA) has also been used as a source of transplantable osteogenic connective tissue progenitors. This study was designed to characterize the performance of a scaffold comprising rhBMP-2/ACS in which the sponge wraps around tricalcium phosphate hydroxyapatite granules (rhBMP-2/ ACS/TCP-HA) and to test the hypothesis that addition of BMA will improve the performance of this construct in the Canine Femoral Multi Defect Model. In each subject, two sites were grafted with rhBMP-2/ACS/TCP-HA scaffold loaded with BMA clot and two other sites with rhBMP-2/ACS/TCP-HA scaffold loaded with wound blood (WB). After correction for unresorbed TCP-HA granules, sites grafted with rhBMP-2/ACS/TCP-HA+BMA and rhBMP-2/ACS/TCP-HA+WB were similar, with mean percent bone volumes of $10.9 \% \pm 1.2$ and $11.2 \% \pm 1.2$, respectively. No differences were seen in quantitative histomorphometry. While bone formation using both constructs was robust, this study did not support the hypothesis that the addition of unprocessed bone marrow aspirate clot improved bone regeneration in a site engrafted with rhBMP-2/ACS/TCP-HA+BMA. In contrast to prior studies using this model, new bone formation was greater at the center of the defect where TCP-HA was distributed. This finding suggests a potential synergy between rhBMP-2 and the centrally placed ceramic and cellular components of the graft construct. Further optimization may also require more uniform distribution of TCP-HA, alternative cell delivery strategies, and a more rigorous large animal segmental defect model.
\end{abstract}

Keywords: Bone grafting, recombinant human bone morphogenetic protein-2, bone marrow, femoral defect.

\author{
*Address for correspondence: \\ George F. Muschler \\ Department of Biomedical Engineering (ND20) \\ Lerner Research Institute, Cleveland Clinic \\ 9500 Euclid Avenue \\ Cleveland \\ Ohio 44195, USA
}

Telephone Number: 1-216-444-5338

FAX Number: 1-216-444-9198

E-mail: muschlg@ccf.org

\section{Introduction}

The use of recombinant bone morphogenetic protein in the treatment of bone repair has steadily increased over the last decade. Recombinant human bone morphogenetic protein-2, when applied to an absorbable type 1 collagen sponge (rhBMP-2/ACS), is an effective therapy in many bone grafting settings (Boden et al., 2000; Boyne et al., 2005; Burkus et al., 2002; Fiorellini et al., 2005; Govender et al., 2002). When successful, the use of rhBMP-2 can avoid the need to harvest autogenous bone graft and the local acute pain and potential morbidity associated with that surgery. However, rhBMP-2 is not universally successful. Failures of rhBMP-2 treatment are most common in settings of large bone defects and in settings of local tissue deficits resulting from prior injury or infection, tissue loss, scarring or vascular compromise (Tarkin et al., 2010) or as shown in bone healing of tendon to bone in a canine model (Thomopoulos et al., 2012). Optimizing the performance of rhBMP-2 in these settings represents an important clinical goal and challenge that require systematic quantitative examination and potential optimization of multiple variables.

The in vivo and clinical performance of rhBMP-2 and rhBMP-7 is strongly influenced by the scaffold/carrier environment in which it is delivered (Huang et al., 2004; Yilgor et al., 2010). The scaffold/carrier environment influences the presentation and bio-accessibility of rhBMP-2 and particularly the retention of rhBMP-2 within the site. Longer retention of rhBMP-2 in the defect site has been associated with improved performance and reduced dose requirements to achieve the same biological response (Kempen et al., 2008; Kim and Valentini, 2002). Some recent papers have examined different doses of BMP and carriers in order to optimize efficacy and reduce adverse events. However, altering dosages and carriers, such as polycaprolactone (Bae et al., 2011; Yong et al., 2014) or polycaprolactone scaffold with b-tricalcium phosphate (Cipitria et al., 2013), have shown bone formation equivalent to autologous bone graft but not at the level achieved with supraphysiological rhBMP-2/ACS.

The biological response to rhBMP-2 and the related rhBMP-7 is also dependent upon the presence of a responsive cell population and can be modified by the exogenous transplantation of cells to augment the local cell population (Takigami et al., 2007; Yasko et al., 1992). These responsive cells may include local inflammatory cells, endothelial and perivascular cells, and local connective tissue progenitors (CTPs). CTPs have been defined as the heterogeneous population of stem cells and progenitor cells in native tissues that, when activated, are 
capable of proliferating to give rise to progeny that can differentiate into one or more connective tissue phenotypes (Kim and Valentini, 2002). CTPs with the potential to contribute to osteogenesis are denoted as osteogenic CTPs or CTP-Os (Majors et al., 1997).

Surgeons often employ ceramic granules or allograft cancellous bone as adjuvant osteoconductive scaffolds, particularly when the volume in which bone regeneration is desired is large. These materials add compression resistance to the site and can potentially reduce the volume of rhBMP-2/ACS required to fill the defect. In this setting, several positive reports have emerged describing the use of a graft comprising rhBMP-2/ACS in which the sponge is wrapped around morselized granules (Dawson et al., 2009; Jones et al., 2008; Kinsella et al., 2011; Suh et al., 2002). The biological premise of this method is to distribute the biologically active rhBMP-2 bound to the ACS around the periphery of the graft where it will have greatest access to a responsive cell population, while providing an osteoconductive core within the defect site which will promote ingrowth of an osteogenic response that begins on the surface into the center of the defect. This osteoconductive effect may include enhancement of the attachment, migration, proliferation, differentiation, and survival of CTP-Os and other cells. It is also possible that ceramic granules may interact with rhBMP-2 that is released from the ACS sponge through selective or nonselective binding domains to improve the presentation and retention of rhBMP-2 at the site, enhancing the local biological response.

Bone marrow aspiration (BMA) from the human pelvis has been characterized to provide a mean of approximately 1000 CTP-Os per mL (Muschler et al., 1997). Aspiration in small volumes ( $2 \mathrm{~mL}$ or less) from multiple sites improves the concentration and prevalence of CTP-Os in an aspirate sample (Muschler et al., 1997). However, the concentration and prevalence of cells and CTP-Os significantly vary from patient to patient (Majors et al., 1997; Muschler et al., 1993). BMA has also been used for decades as a source of transplantable osteogenic connective tissue progenitors (CTP-Os) (Muschler et al., 2004). Several uncontrolled clinical series support the clinical value of aspirated marrow (Caralla et al., 2013; Muschler et al., 1993; Muschler et al., 2004). Connolly and coworkers reported successful clinical treatment of 20 non-unions, and went on to show that concentrating marrow-derived cells using intraoperative processing might be used to improve outcome (Connolly et al., 1989; Connolly et al., 1991; Tiedeman et al., 1991). Hernigou, and coworkers have also reported clinical success in using marrow buffy coat preparations in treating non-unions and avascular necrosis (AVN) lesions (Hernigou et al., 2006; Hernigou et al., 2005a; Hernigou et al., 2005b).

Optimal utilization of rhBMP-2, particularly in settings of large bone defects and in areas of prior trauma, scarring and tissue loss, has not been established and may require a combination of rhBMP-2 with both osteoconductive materials as well as an exogenous source of responsive cells. This study was designed to characterize the performance of a bone graft comprising rhBMP-2/ACS in which the sponge is wrapped around tri-calcium phosphate-hydroxyapatite (TCP-HA) granules (rhBMP-2/ ACS/TCP-HA) and to test the hypothesis that addition of BMA will improve the performance of this construct in the established Canine Femoral Multi Defect (CFMD) Model (Caralla et al., 2013; Luangphakdy et al., 2013; Takigami et al., 2007).

\section{Materials and Methods}

\section{Animals and experimental design}

This study was conducted after approval from the Cleveland Clinic Institutional Animal Care and Use Committee. Study animals were cared for in accordance with the Principles of the guide for the Care and Use of the Laboratory Animals. Ten skeletally mature research purpose-bred female coonhounds (31.6 $\pm 2.2 \mathrm{~kg})$, age ranging from 1-3 years (mean, 1.9 years) were utilized.

\section{Implant materials and graft preparation}

A composite graft material composed of rhBMP-2, collagen and TCP granules was used as the implant material in all defect sites. Implant materials were provided by Medtronic Spinal Division (Memphis, TN, USA), including: rhBMP-2 in solution $(0.2 \mathrm{mg} / \mathrm{mL})$; absorbable Type 1 bovine collagen sponge (ACS) carrier; and TCP-HA granules (Mastergraft ${ }^{\circledR}$ ceramic resorbable granules, $85 \% \mathrm{TCP} / 15 \% \mathrm{HA}, 500 \mu \mathrm{m}$ average pore size, $1.6-3.2 \mathrm{~mm}$ granule diameter). Graft composites were prepared intraoperatively as follows: 1) the ACS carrier was trimmed to dimensions of $1.8 \mathrm{~cm}$ (width) $\times 3.2 \mathrm{~cm}$ (length) $\times 0.35 \mathrm{~cm}$ (thickness); 2) the ACS was wetted with $0.5 \mathrm{~mL}$ rhBMP-2 solution and allowed to stand undisturbed for $15 \mathrm{~min}$ at room temperature; 3 ) granules $(0.5 \mathrm{~mL})$ were distributed uniformly over a $2 \mathrm{~cm}$ length of the ACS; 4) $0.5 \mathrm{~mL}$ of clotted bone marrow aspirate (BMA) or $0.5 \mathrm{~mL}$ clotted wound blood (WB) was layered over the granules and sponge (Fig. 2a); and 5) the graft composite was then rolled, without compression, into a $10 \mathrm{~mm}$ diameter $\times 15 \mathrm{~mm}$ height cylinder (Figs. $2 \mathrm{~b}$ and 2c). A $0.45 \mathrm{~mm} \mathrm{~K}$-wire was passed through the center of the defect as a "tooth pick" allowing the graft to be handled and placed into the defect site without compression.

\section{Bone marrow aspiration and preparation of nucleated cells}

Bone marrow was aspirated percutaneously in $1 \mathrm{~mL}$ aliquots from the proximal humerus using a Lee-Lok bone marrow aspiration needle (Lee Medical Ltd, Minneapolis, MN, USA) as the first step in each surgical procedure to insure that a systemic effect of marrow aspiration did not confound the outcome. Previous experience has demonstrated that the canine proximal humerus is a reliable source of hematopoietic bone marrow containing osteoblastic progenitors, with yields of nucleated cells and CTP-Os that are comparable to human iliac crest aspirates (Muschler et al., 1993). $1 \mathrm{~mL}$ wound blood was collected by aspiration during soft tissue exposure. 


\section{Operative procedure}

Twelve hours prior to the surgery, a fentanyl transdermal patch $(100 \mu \mathrm{g} / \mathrm{h})$ was placed. Subjects were pre-medicated with penicillin $\mathrm{G}$ (1.2 million units IM) and atropine $(0.044 \mathrm{mg} / \mathrm{kg} \mathrm{IM})$ on the morning of the surgery day. General anesthesia was initiated using Pentothal $(20 \mathrm{mg} /$ $\mathrm{kg} \mathrm{IV)} \mathrm{followed} \mathrm{by} \mathrm{intubation} \mathrm{and} \mathrm{inhalation} \mathrm{of} \mathrm{closed}$ isoflurane (0.5-3 \%) inhalation. After positioning in a right lateral position, the left femur was shaved, prepped, and draped in a sterile fashion. A $10 \mathrm{~cm}$ skin incision was made along the longitudinal axis of the femur beginning just distal to the greater trochanter. Deep fascia was incised between the biceps femoris and the vastus lateralis and these muscles were bluntly separated. The femur was exposed in an extraperiosteal plane by elevating the vastus lateralis. A customized drill template was fixed longitudinally on the lateral aspect of the femur with two $3.5 \mathrm{~mm}$ bicortical screws (Synthes USA, Paoli, PA, USA). Four identical $10 \mathrm{~mm}$ diameter $\times 15 \mathrm{~mm}$ long unicortical cylindrical defects were created in the metaphysis and the proximal diaphysis of the femur (Fig. 1). Defects were spaced such that the outer edge of each defect was $1.5 \mathrm{~cm}$ from the outer edge of the adjacent defect to avoid interactions between defect sites. The template was removed. A $1.0 \mathrm{~cm}$ diameter by $1.5 \mathrm{~cm}$ long stainless steel spacer was placed in each defect temporarily to allow hemostasis to be achieved without formation of a clot of wound blood in the space that was preserved for the scaffold. Bone graft composites were placed in each defect as described above (Fig. 2d). To insure equal distribution of each material by sites and to allow control and testing for both material effects (differences between test groups) and site effects (differences in performance based on the site of implantation), the test materials in the two groups in each animal were distributed in a predetermined distribution pattern among the 4 sites, using either an "ABBA" or "BAAB" configuration. Following this, a customized stainless steel plate was fixed to the femur using two $3.5 \mathrm{~mm}$ cortical screws passed through the screw sites to fix the drill template to the femur. This plate was designed to avoid the risk of pathologic fracture by protecting the grafted region from excessive bending and rotational stress. Deep fascia and subcutaneous tissue were sutured using 1-0 and 2-0 vicryl sutures. Stainless steel staples were used for closure of skin.

\section{Post-operative care}

Subjects were housed in canine runs with free mobility and access to food and water. Agitation in the early post-operative period was managed as needed using acepromazine $(0.1 \mathrm{mg} / \mathrm{kg} \mathrm{SQ})$. Post-operative pain was managed with the transdermal fentanyl patch $(100 \mu \mathrm{g} / \mathrm{h})$.

Subjects were euthanized four weeks post-operatively with a lethal dose of pentobarbital sodium $(5 \mathrm{~mL} / 5 \mathrm{~kg})$. After the plate covering the defects was removed, the femur was explanted and cleaned of adhering tissue. Individual graft sites were separated using a band saw. Each site was fixed in $10 \%$ neutral buffered formalin. After $48 \mathrm{~h}$, the solution was replaced with $70 \%$ ethanol to prevent demineralization.

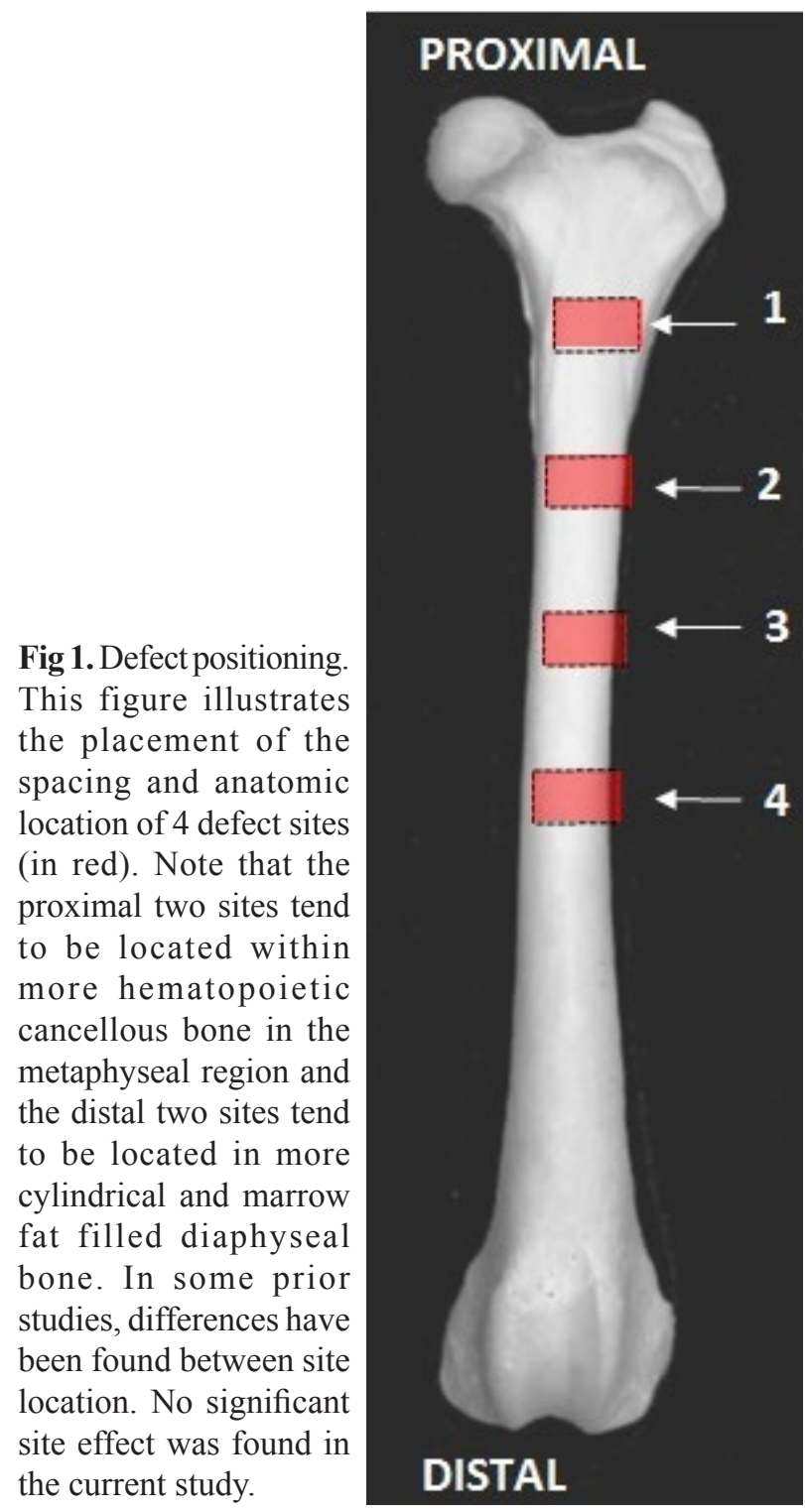

\section{MicroCT processing and analysis}

Quantitative assessment of the graft site was performed using micro-computed Tomography (microCT) and threedimensional segmental image post-processing.

Each specimen was placed on the scanning platform of a GE eXplore Locus mCT (GE Healthcare, Milwaukee, WI, USA) in the cranial-caudal axis, parallel to the direction of table travel and $720 \mathrm{X}$-ray projections were acquired. The system was operated at $80 \mathrm{kV}, 490 \mu \mathrm{A}$, with an exposure time of $525 \mathrm{~ms}$ per individual projection. A dark-field (X-ray beam turned off), a bright-field (X-ray beam turned on with no sample in beam), and density calibration phantom (hydroxyapatite, solid water, air) images were taken at the end of each imaging session for correction of the X-ray projection data (dark- and bright-field normalization, ring artifact reduction, and CT attenuation to Hounsfield Unit conversion during projection reconstruction). Projection images were preprocessed and reconstructed into $3 \mathrm{D}$ volumes ( $45 \mu \mathrm{m}$ resolution) on a $16 \mathrm{PC}$ reconstruction cluster using a modified tent-FDK cone beam algorithm (GE reconstruction software). 
Fig. 2. Composite graft preparation. (a) The rhBMP-2/ ACS sponge (ACS sponge hydrated with solution containing rhBMP-2) is layered with the TCP-HA scaffold and with either bone marrow clot or blood clot; (b) the sponge is rolled without compression into a cylinder; (c) $\mathrm{rhBMP}-2 / \mathrm{ACS} / \mathrm{TCP}-\mathrm{HA}$ cylindrical scaffold (dimension $1 \mathrm{~cm}$ in diameter $\times 1.5 \mathrm{~cm}$ in height; and (d) four grafted defect sites in the left femur.
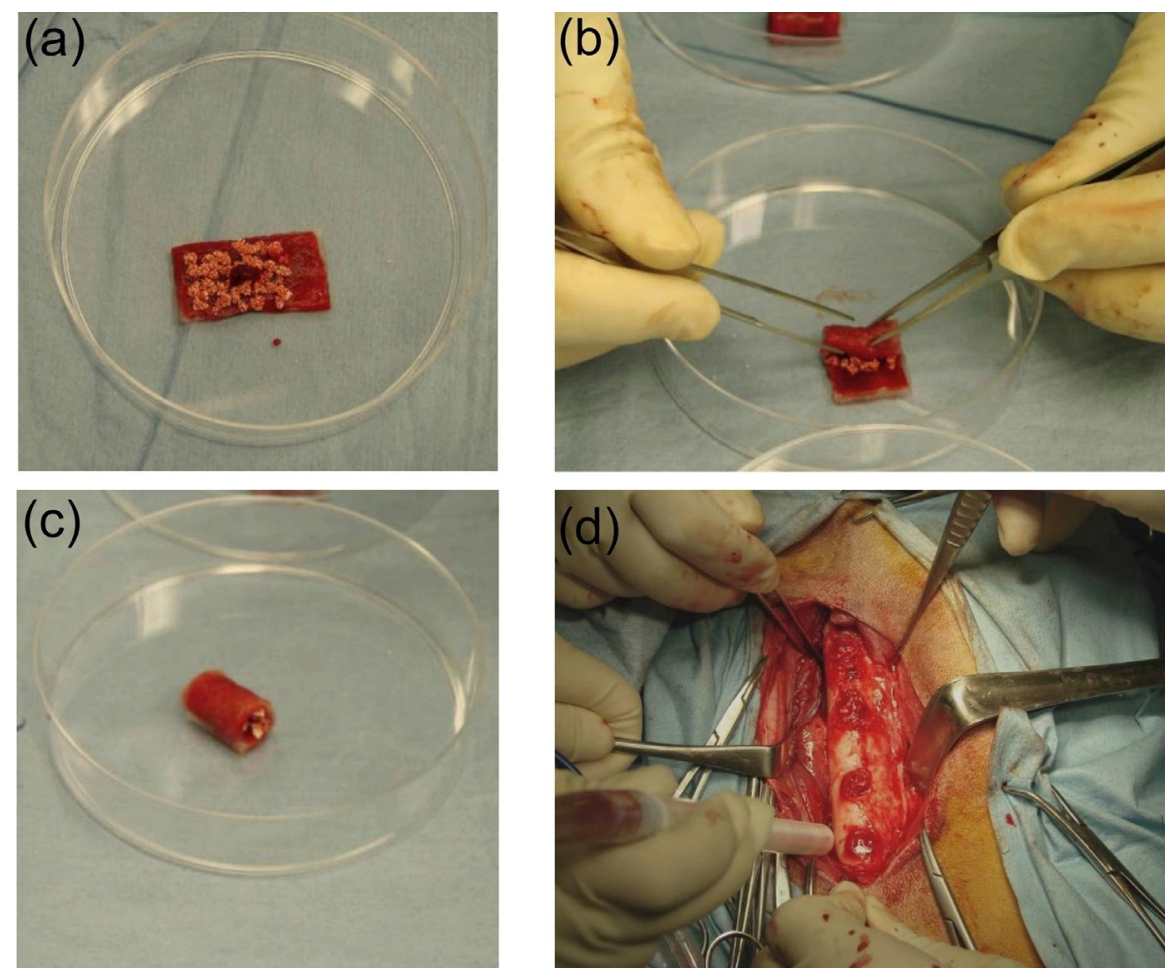

(a)
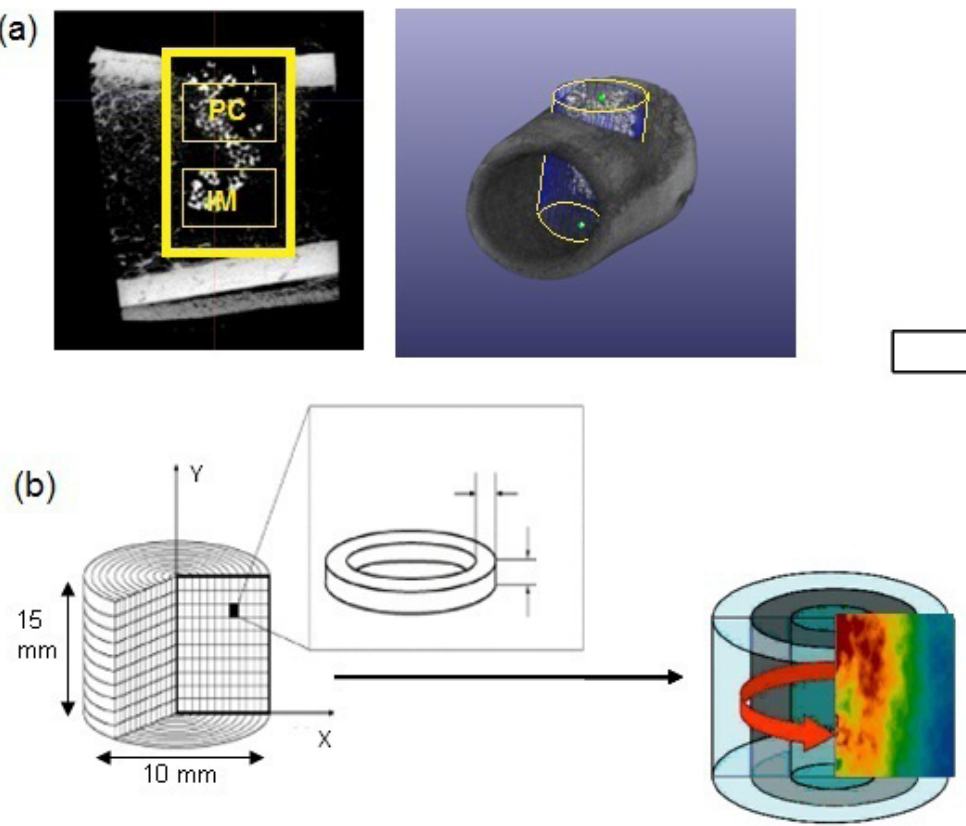

(c)

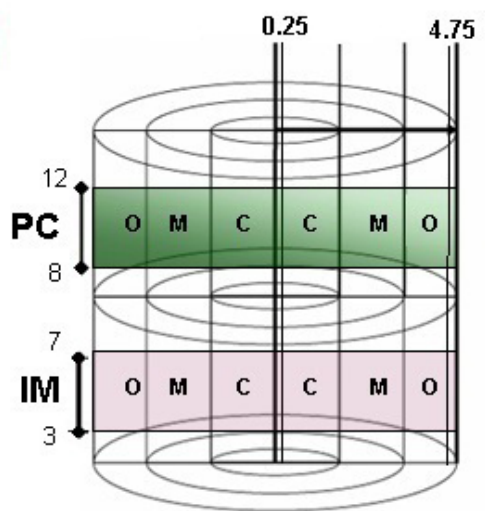

Fig. 3. MicroCT analysis protocol. (a) 3D MicroCT scans are visualized and each defect region is defined (outlined blue); (b) 3D microCT defect volume is collapsed into a 2D color contour plot illustrating the fraction (\%) of voxels at each vertical and radial location within the defect that is above bone density (\% Bone volume); and (c) the regions of interest for both CT and histology analysis are defined. PC (Pericortical) region and IM (Intramedullary) region are defined based on vertical position within the defect. Subsequent histological analysis is also divided into $\mathrm{C}$ (Center) region, $\mathrm{M}$ (Middle) region, $\mathrm{O}$ (Outer) regions, based on the defined radial regions measured from the center of the defect.

Each specimen was analyzed with a segmentation software developed in-house, in which a 3-dimensional cylindrical "defect template" volume, $10 \mathrm{~mm}$ in diameter and $15 \mathrm{~mm}$ in length size, was manually positioned to define the boundaries of the defect site using the circular introitus and marks from the flat finishing drill on the opposite cortex as fiduciary guides (Fig. 3a).
Regions of new bone formation within the defect site were identified based on calibrated Hounsfield Units (HU) within each specimen to provide reproducible thresholding across all specimens. For 3D reconstruction, each volume was scaled to Hounsfield Units (HU) using the calibration phantom. Each specimen was visualized as a $3 \mathrm{D}$ volume using MicroView software (GE Healthcare, Milwaukee, 

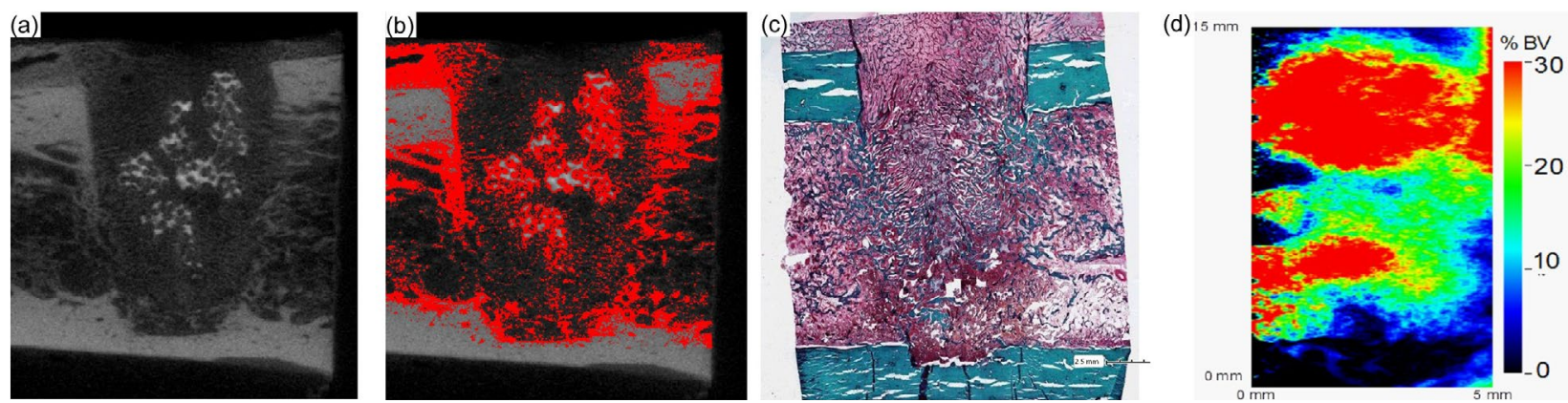

Fig. 4. Illustration of segmentation of regions of different mineral density into TCP-HA, new bone, and non-bone regions. CT analysis required segmentation of each volume element (voxel) in each CT scan into one of these three categories for analysis. These images illustrate one example of this process. (a) Traditional "bone window" MicroCT Scan using a grey scale range that includes all tissues. (b) Segmented CT slice in which voxels with density too low to be bone (less than $1000 \mathrm{HU}$ ) are black, voxels with intermediate density (1000 to $2100 \mathrm{HU}$ ) suggesting new bone formation are colored red regions, and voxels with density to high to suggest new bone formation (over $2100 \mathrm{HU}$ ) are colored white. Note that this last group includes most of the cortical bone in the slice and also selected regions within the defect site that correspond to regions of residual TCP-HA. (c) Histology from this same sample, as close as possible to the CT section demonstrates residual TCP-HA scaffold material with an estimated new bone area of $21.4 \%$ and residual TCP-HA area of $8.5 \%$. (d) The \% BV heat map from this CT slice provides a mean $\%$ BV volume of $22.3 \%$ and mean $\% \mathrm{BV}$ that was excluded as residual TCP-HA scaffold of $7.1 \%$.

(a)

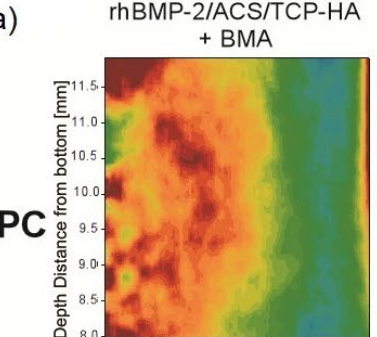

Radial Distånce from center [mm

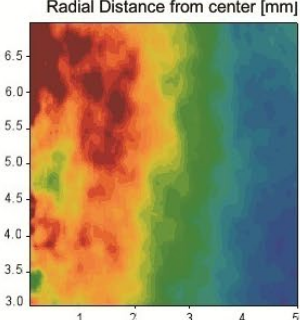

Overall Mean \% BV $=17.5 \%+1.2 \%$
rhBMP-2/ACS/TCP-HA

+ WB
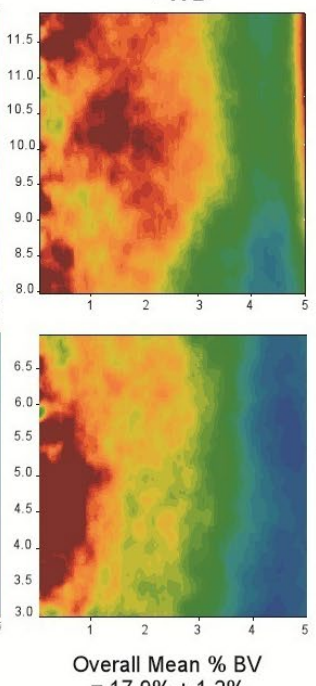

$=17.9 \%+1.2 \%$ (b)

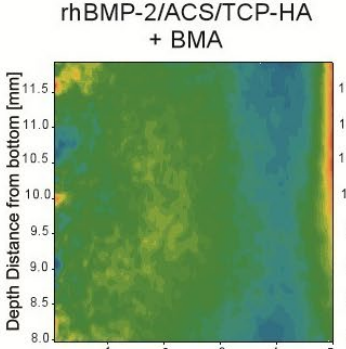

Radial Distance frơm center [mm

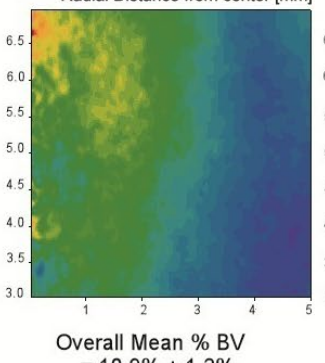

$=10.9 \%+1.2 \%$
rhBMP-2/ACS/TCP-HA

+ WB
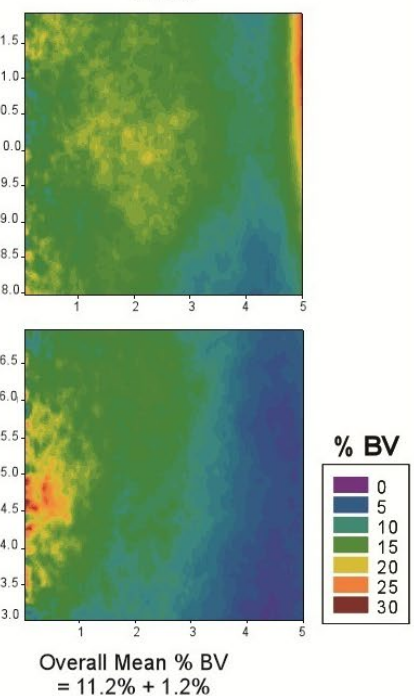

Fig. 5. The pattern and distribution of bone formation within the pericortical (PC) region and the intramedulary (IM) region is illustrated in 2D color contour plots. The outside edge or perimeter of each defect is on the far right of each plot and the center is at the far left. Vertical position within the defect is indicated on the y-axis. (a) Overall mineral density. The distribution of overall mean mineral density within all defects is illustrated for both the +BMA graft sites (left) and the +WB graft sites on the right. These data include mineral density attributed to residual TCP-HA. (b) Overall mineral density subtracting residual TCP-HA. The distribution of mineral density attributed to new bone formation is illustrated.

WI, USA). A skilled operator who was blinded with respect to the material being assessed used the native bone tissue outside of the defect site as a reference to define, for each sample: 1) a lower bone threshold which excluded soft tissue, but was below the density of native trabecular bone and any periosteal new bone formation evident in the sample, and 2) an upper density threshold, which excluded voxels with a density that was too high to be considered as new bone formation and therefore indicative of unresorbed TCP-HA granules, balancing partial volume effects. This upper threshold was set as a level that excluded all voxels that were at or above the density of native cortical bone, based on the rationale that little of the new bone formation present in the defect could achieve the mineral density of cortical bone by four weeks after grafting and that any voxel with a density that was equal to or greater than the density of native cortical bone must be assumed to represent residual TCP-HA granules.

The mean upper and lower thresholds for the two groups were not different for the BMA group (1935 HU \pm 141 and $1140 \mathrm{HU} \pm 74$, respectively) and for the WB group (1907 HU \pm 96 and $1115 \mathrm{HU} \pm 87$, respectively). 
The analysis of microCT data using the high threshold resulted in the exclusion of a mean of $3.4 \% \pm 3.4$ of the volume of the defects in the BMA group and $3.7 \%$ \pm 3.9 of the volume of the defects in the WB group, as probably residual TCP-HA scaffold. These thresholds were qualitatively validated, by comparison to the amount of residual ceramic material that was seen on $2 \mathrm{D}$ histological sections from both groups, as shown in Fig. 4, and did not statistically differ between groups.

Summary data to illustrate the pattern and extent of mineralization in the defects in each group were generated by projecting a mean percent Bone Volume ( $\%$ BV) using a $2 \mathrm{D}$ color map ranging from $0 \%$ (purple) to $30 \%$ (red), as shown in Fig. 5. To eliminate the inclusion of confounding sampling artifacts in the analysis, regions of the top, bottom, periphery and center of the defect were excluded from analysis (Fig. 3c). The 3-mm regions from the top and bottom of the defect were excluded to eliminate the potentially confounding effects associated with periosteal tissue reaction at the top of the defects and reactive endosteal tissue reaction at the base of the defect. Data from the very edge $(4.75-5.0 \mathrm{~mm}$ from the center) were excluded to avoid inclusion of existing cortex at the edge of the defect in the analysis. The very center $(0-0.25 \mathrm{~mm})$ was also excluded from analysis due to the vanishing small sampling volume that is assessed as one approaches zero in the defect and the increased variability that this creates in data from the very center. Specific regions of interest were defined for analysis based on vertical position and radial position within the defect site (Fig. 3). The pericortical (PC) region was defined as that region between 8 to $12 \mathrm{~mm}$ from the bottom of the grafted site. The intramedullary (IM) region was defined as that region between 3 to $7 \mathrm{~mm}$ from the bottom of the grafted site. Similarly, center $(C)$, middle $(\mathrm{M})$, and outer $(\mathrm{O})$ regions of the defect were defined based on radial positions from 0.25 to $1.75 \mathrm{~mm}, 1.75$ to $3.25 \mathrm{~mm}$, and 3.25 to $4.75 \mathrm{~mm}$ from the center, respectively.

\section{Histology analysis}

Histology was assessed at the Bone Histomorphometry Laboratory at Mayo Clinic using $50 \%$ sub-sampling of defect sites for both BMA and WB groups, 20 specimens for each scaffold. Each specimen was dehydrated in a graded series of alcohols, and embedded in polymethylmethacrylate without decalcification. A Leica RM 2265 microtome was used to section $5 \mu \mathrm{m}$ thick specimens along the long bone axis, one third into the defect site toward the middle of the defect site, and stained with modified Goldner's Trichrome and hematoxylin and eosin (H\&E). Sections were scanned using a NanoZoomer Digital Pathology System (Hamamatsu, Bridgewater, NJ, USA). Histomorphometry analysis was performed using the software package IHC score (Bacus Laboratories Inc., Lombard, IL, USA) based on Goldner's trichrome stained slides, with specific assessment of the area of new bone formation (including unmineralized osteoid), vascular spaces, fibrous tissue, fat, hematopoietic bone marrow, residual TCP-HA material and void space (unstained white regions).

\section{Statistical analysis}

Statistical Analysis was performed using SAS ${ }^{\circledR}$ software $9.2\left(\mathrm{SAS}^{\circledR}\right.$, Cary, NC) and $\mathrm{JMP}^{\circledR}$ 9.0.0 software $\left(\mathrm{SAS}^{\circledR}\right.$, Cary, NC). An ANOVA model was used to test for differences between scaffolds (rhBMP-2/ACS/TCP-HA with BMA clot or with WB clot), sites (proximal or distal), depth regions (PC or IM), and radial distance (Center, Middle or Outer). The effect of canine was included as a random factor. All two-way interactions were included in the model. The results are expressed as mean \pm standard error (SE) of pooled estimate. Statistical significance was reached if $p<0.05$.

\section{Results}

All subjects completed the planned procedure and outcome assessment without surgical or postoperative complications. Animals usually returned to full weightbearing by two days post-operation.

\section{MicroCT assessment of bone formation}

The 2-D contour plots of mean \% BV based on distance from the center of the defect (x-axis) and distance from the bottom of the defect (y-axis) across all samples for each material are presented in Fig. 5. These data are separated into plots of the pericortical region (top) and intramedullary regions (bottom).

In Fig. 6, the same mean \% BV data per graft combination are presented as $2 \mathrm{D}$ overlay plots that illustrate the quantitative change in $\% \mathrm{BV}$ relative to radial position within the defect. Mean \% BV data calculated in the overall defect volume is presented in Fig. 6a, and mean \% BV data in the PC and IM regions are presented in Fig. 6b. These plots illustrate that marked differences in $\%$ BV were seen between scaffolds in the outer, middle and center region of the defect site. Mean $\% \mathrm{BV}$ was greatest in the center region of the defect sites (between 0.25 to $1.75 \mathrm{~mm}$ from the center). It decreased moving away from the center through the middle and into the outer regions of the defect, except at the very periphery of the defect (4$4.75 \mathrm{~mm}$ ) where mean $\% \mathrm{BV}$ increased again. This central distribution of mean $\% \mathrm{BV}$ persisted in the data even after exclusion of the mean \% BV associated with very dense voxels associated with unresorbed TCP-HA granules (Fig. 5b). After adjusting mean \% BV measurement for unresorbed TCP-HA, the mean $\% \mathrm{BV}$ for rhBMP-2/ACS/ TCP-HA with BMA clot was $10.9 \% \pm 1.2$ and mean $\% \mathrm{BV}$ for rhBMP-2/ACS/TCP-HA with WB clot was $11.2 \%$ \pm 1.2 in the overall defect region. The difference between the addition of BMA clot and WB clot was not statistically significant in the defect overall or in any localized region of interest (PC region $v s$. IM region or Center $v s$. Middle vs. Outer Region). Mean \% BV between all proximal sites $(11.8 \% \pm 1.2)$ and all distal sites $(10.3 \% \pm 1.2)$ was not significantly different $(p=0.09)$.

\section{Histology data}

Representative images for each material are provided in Fig. 7. Both rhBMP-2/ACS/TCP-HA with BMA clot and 
(a)

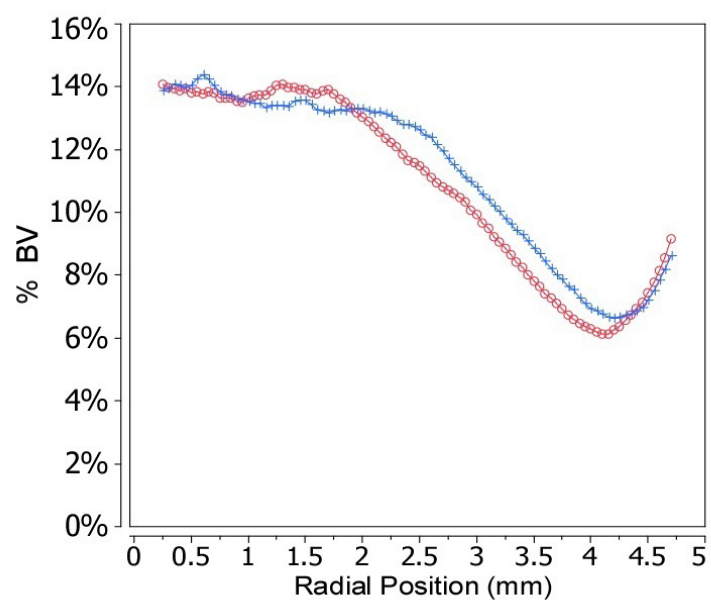

a- rhBMP-2/ACSTTCP-HA + BMA + rhBMP-2/ACS $/ T C P-H A+W B$ (b)

\section{Intramedullary and Pericortical Regions}

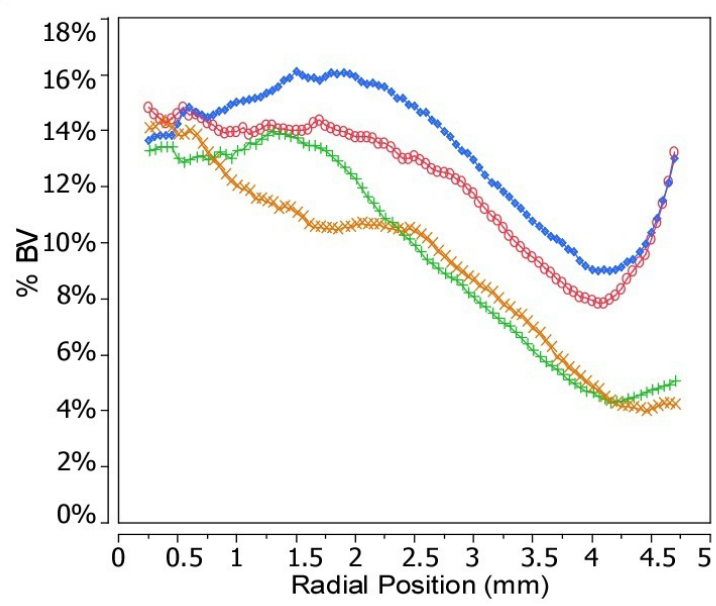

$\begin{array}{ll}\text { D-PC_rhBMP-2/ACS/TCP-HA+BMA } & +-I M \_r h B M P-2 / A C S / T C P-H A+B M A \\ \text {-PC_rhBMP-2/ACS/TCP-HA+WB } & \times-I M \text { rhBMP-2/ACS/TCP-HA+WB }\end{array}$

Fig. 6. Center to edge distribution of new bone mineral. These 2D Overlay plots illustrate the radial distribution of mean $\%$ BV between the two groups, after excluding voxels with density consistent with residual TCP/HA granules: (a) in the overall defect volume, and (b) separating PC and IM regions.

\section{(a) rhBMP-2/ACS/TCP-HA + BMA}

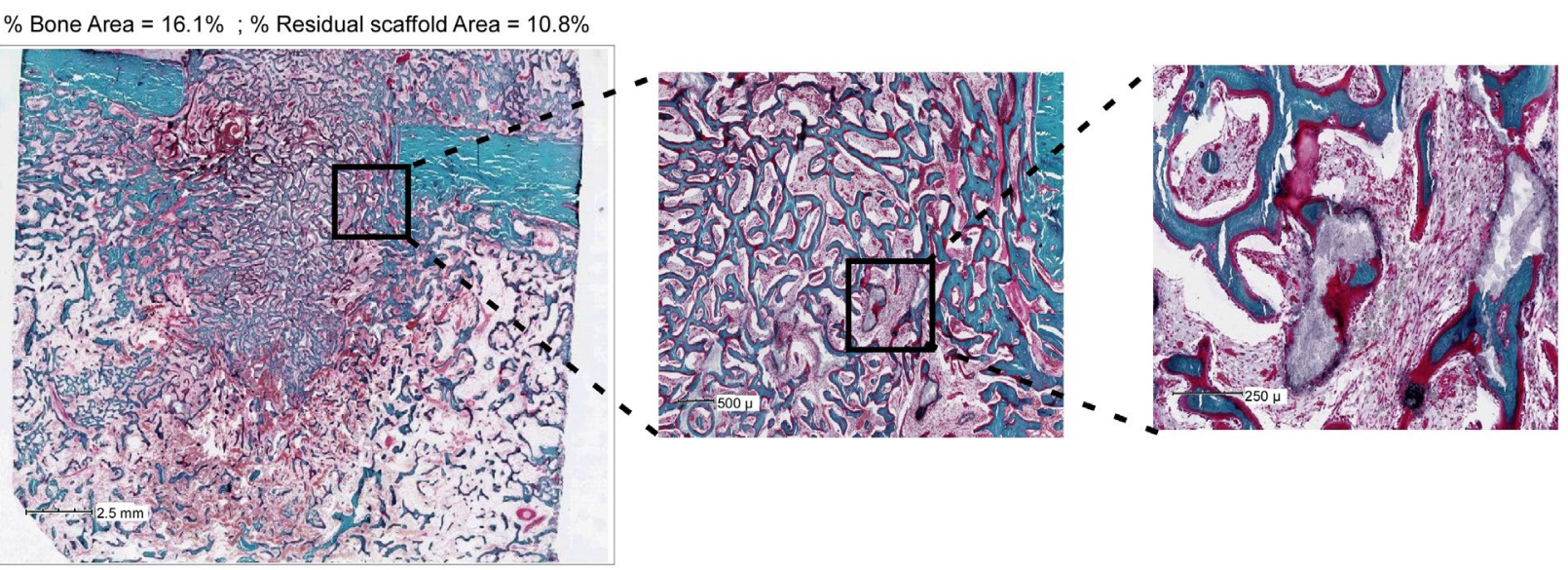

\section{(b) rhBMP-2/ACS/TCP-HA + WB}

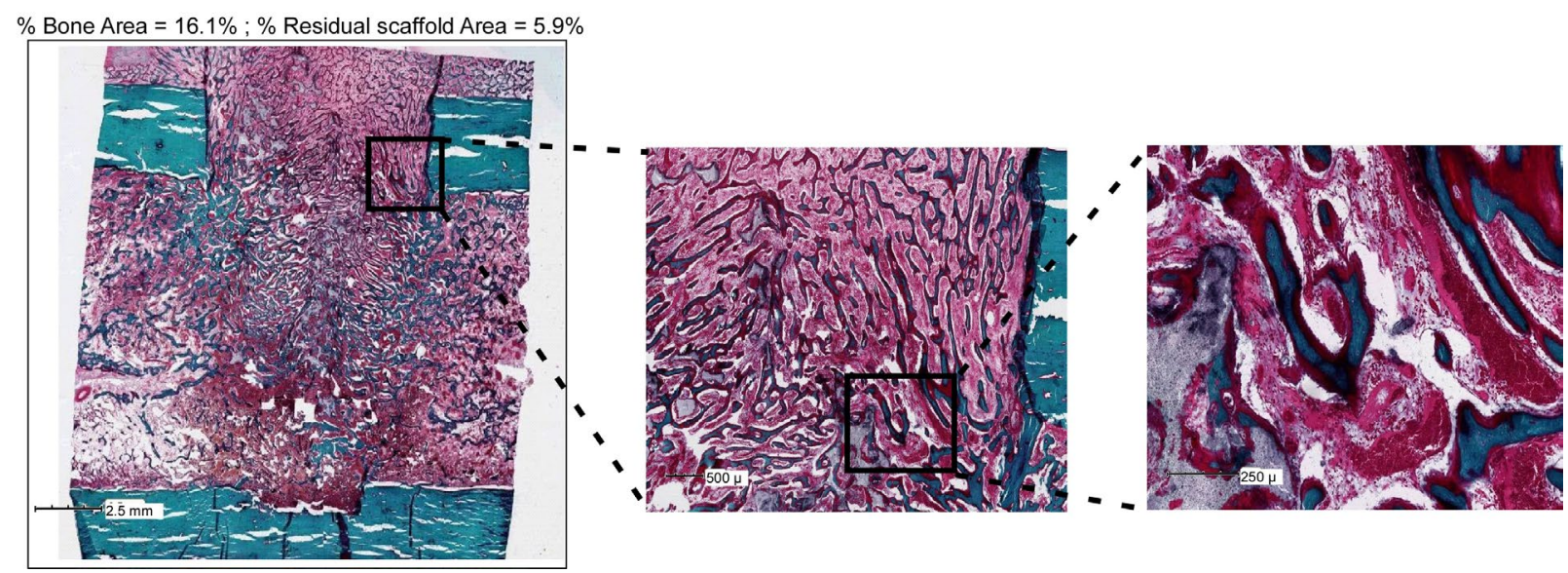

Fig. 7. Histological appearance and evidence of residual TCP-HA scaffold. Two representative defect sites are presented using Goldner's stain. Each histological section is $5 \mu \mathrm{m}$ thick, cut parallel to the long axis of the bone and located near the center (green, mineralized bone; red, unmineralized osteoid; grey, residual TCP-HA graft; and white, non occupied space). (a) rhBMP-2/ACS/TCP-HA +BMA sample; (b) rhBMP-2/ACS/TCP-HA +WB sample. Residual TCP-HA scaffold can be seen in both high powered images on the right. 

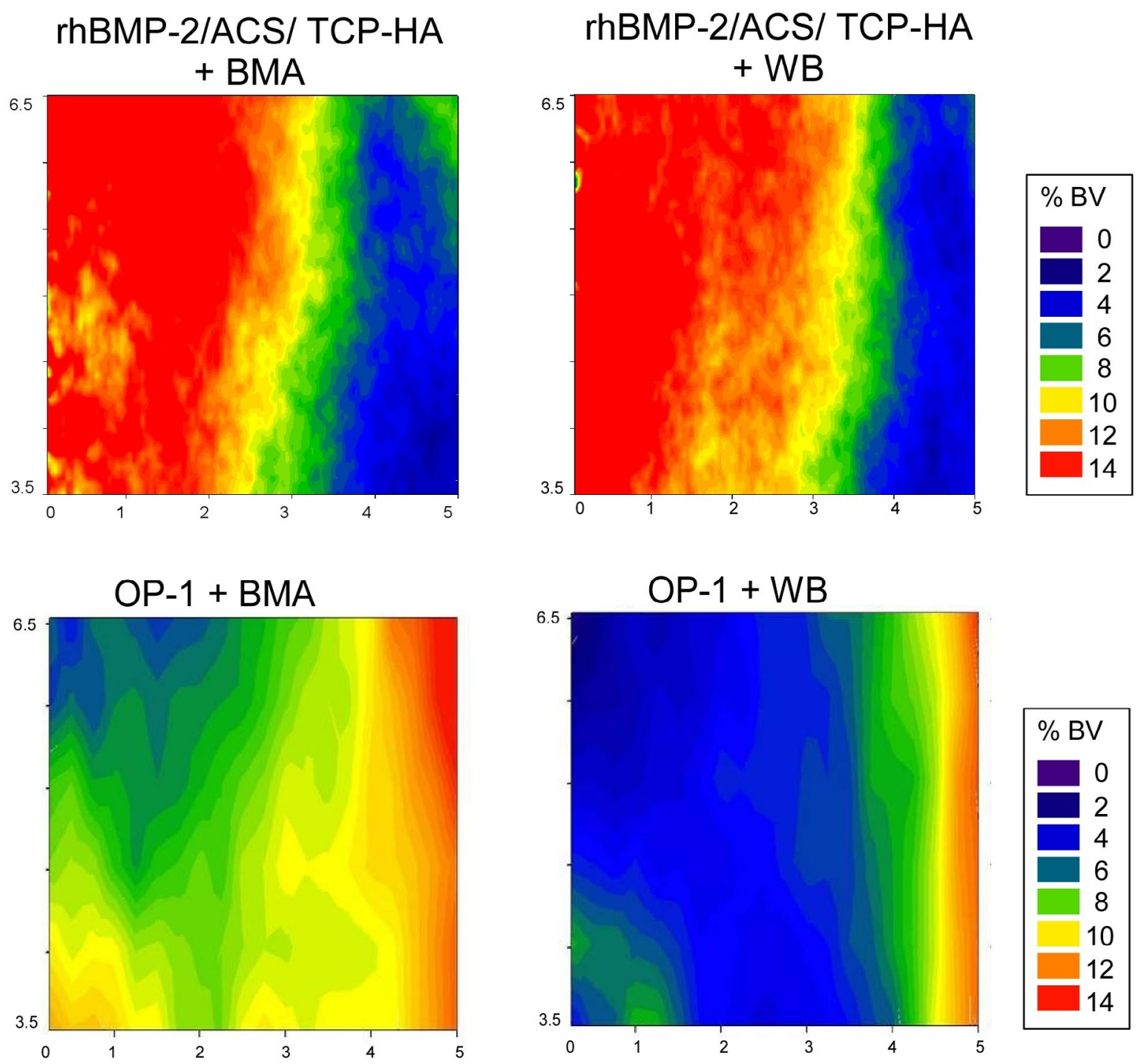

Fig. 8. Comparison to historical data using OP-1 in the CFMD model. These images compare the pattern distribution of new bone mineral density in the IM region between the current study and a prior published report using OP-1. Note that the color scale for $\% \mathrm{BV}$ for data from the current study has been reduced from $0-30 \%$ to $0-14 \%$ to allow better visualization of differences in the pattern of mineralization. Bone formation with OP-1 was greatest on the outside of the defect, and was enhanced using BMA. In contrast, new bone formation in the current study (both on CT and confirmed histologically) occurred preferentially in the center and middle regions of depth, corresponding to the location where TCP-HA granules were distributed.

with WB clot showed robust bone formation. An extended interconnected network of trabecular bone was generally present with significant areas of unmineralized osteoid and frequent vascular spaces. New bone was present on the surface of unresorbed TCP/HA granules. Active remodeling by osteoclasts was a minor component in the implant area. Unresorbed TCP/HA granules were present throughout most of the inner and center region of the defect, but occupied a small fraction of the total defect area (less than $10 \%$ ). Several defects demonstrated small cystic cavities which were non-inflammatory in nature and consistent with prior observations of cystic change with rhBMP-2 implant sites. H\&E slides showed no evidence of inflammation in response to the rhBMP-2/ACS/TCP/ HA graft.
Quantitative histomorphometry provided estimated percent bone area metrics which were very close to the $\% \mathrm{BV}$ data provided by microCT. The mean percent area of new bone tissue for rhBMP-2/ACS/TCP-HA+BMA clot was $17.9 \% \pm 1.3$. The mean percent area of bone tissue for rhBMP-2/ACS/TCP-HA+ WB clot was $16.9 \% \pm 1.7$. Mean percent bone area of residual TCP-HA scaffold was similar in both the BMA and WB groups at $8.8 \%$ \pm 0.8 and $8.2 \% \pm 1.2$, respectively. These histology data, which selectively sample the center of the defect more than the periphery of the defect, are consistent with the data obtained in the microCT analysis and suggest that the thresholding methods used in the microCT analysis were appropriate. 


\section{Discussion}

This study did not support the hypothesis that the addition of unprocessed bone marrow aspirate clot can improve the rate and effectiveness of bone regeneration in a site engrafted with rhBMP-2/ACS/TCP-HA, using a technique that involved rolling both TCP-HA granules and bone marrow clot into the center of a collagen sponge construct, in which rhBMP-2 was adsorbed. Sites grafted with rhBMP-2/ACS/TCP-HA+BMA were found to have mean $\% \mathrm{BV}$ of $10.9 \% \pm 1.2$, after correction for unresorbed TCP granules. Overall mean \% BV for rhBMP-2/ACS/TCP$\mathrm{HA}+\mathrm{WB}$ was $11.2 \% \pm 1.2$. This finding stands in contrast to previous reports that the addition of marrow-derived cells did improve the outcome of bone formation at the site of implantation of rhBMP-2 and the related rhBMP-7 (OP1, Stryker, Kalamazoo, MI, USA) (Takigami et al., 2007; Yasko et al., 1992). One of these two studies (Takigami et al., 2007) was performed using the canine femoral multidefect model that is very similar to the protocol used in the current study (Fig. 8). The other study (Yasko et al., 1992) was performed in a rat segmental defect model, in a much smaller defect. The reason for the discrepancy between the finding of this study and prior studies may relate to the method of cell transplantation. In the two prior studies, marrow-derived cells were mixed into the implanted graft material in a manner that distributed them throughout the implant. As a result, many of the implanted cells were positioned near the surface of the implant, where their survival would be more likely due to the short diffusion path, while many if not most cells would be positioned within the graft material at a depth of $1 \mathrm{~mm}$ or more from the surface, where survival would be more likely to be threatened by hypoxia. The differential survival of cells positioned near the surface and those positioned deeper within the graft site is both supported by theoretical principles of mass transport (Muschler et al., 2004) and is further supported by the finding of Takigami et al. (2007), that the increase in bone formation that resulted from the addition of marrow-derived cells was limited to the portion of the grafted volume that was within 1.5 and $3.5 \mathrm{~mm}$ from the surface of the implant.

In the current study, unprocessed clotted bone marrow containing marrow-derived progenitors was layered onto the surface of the ACS sponge along with TCP-HA granules and then rolled into the center of the graft. As a result, the transplanted cells were preferentially positioned in the center of the graft, away from the outer surface. This sequestration of the transplanted cells in the center of the graft may have resulted in the loss of transplanted cells due to hypoxia-induced apoptosis and necrosis, precluding a biological contribution of the transplanted cells to the outcome of bone formation. The integration of these findings suggests that future studies seeking to optimize the transplantation of osteogenic cells for bone regeneration should carefully consider the distribution of transplanted cells and ensure that many, if not all, transplanted cells are preferentially positioned near the surface of the implant.

The CFMD model is, by design, a screening model and not a critical sized segmental defect model. It has the benefit of being a large animal model that allows rapid assessment of early performance of bone regeneration strategies in which four data points are available from each animal, enabling control for variation between animals and limitation of the number of animals needed to measure relevant differences between materials. We have recently published a review and discussion of animal models for assessment of bone grafting materials (Muschler et al., 2010).

The surface of the graft site is comprised of healthy vascular tissue, including periosteum, endosteum and intramedullary marrow. As such, the surface of the graft site will contain both a source of oxygen via diffusion and a source of both angiogenic and osteogenic cells. This environment enables the assessment of the relative osteoconductive effect of scaffold materials that are placed into the defect (Caralla et al., 2013; Luangphakdy et al., 2013). This environment also enables the assessment of the biological effect of an implant containing bioactive molecules such as rhBMP-2, because the implant site contains a population of local progenitors which serves as a target population on which the bioactive agent may act (Takigami et al., 2007 ).

The CFMD model is also designed to enable the efficient evaluation of the potential efficacy of cell processing and transplantation strategies. In a series of studies, we have demonstrated that aspiration of bone marrow from the canine proximal humerus provides a composition of cells and osteogenic progenitors that is comparable to aspiration samples from human iliac crest. While the defect sites in the CFMD model are comprised of healthy and freshly traumatized bone tissue at the periphery of the defect, the composition of cells, and particularly the concentration and prevalence of osteogenic progenitors, is unlikely to be optimized. As a result, modification of the local cell population to enhance the local progenitor population is likely to improve the performance of a graft material. This premise is supported by the findings of Takigami et al. (2007) that were discussed above. It is also supported by the recent findings of Caralla et al. (2013), who used the CFMD model to evaluate the efficacy of transplantation of marrow-derived cells that had been processed using magnetic separation to concentrate and select osteogenic connective tissue progenitors using a novel marker (hyaluronan). They found that transplantation of this enriched population resulted in increased new bone formation and increased vascularity when compared to unprocessed marrow. However, unlike the current study, the cells transplanted by Caralla et al. were not sequestered in the center of the defect and therefore were more likely to survive transplantation. In aggregate, the integration of information from the Takigami and Caralla papers and the current paper suggests that the CFMD model can be used to assess the efficacy of cell transplantation strategies, provided that some or all of the transplanted cells are positioned near the surface of the implant.

The second major finding in this study, one that was not expected, was the fact that the magnitude of bone formation at four weeks following implantation was greatest near the center of the defect, rather than near the periphery. This finding was true in both the BMA and the WB groups. This finding stands in contrast to all prior studies performed in 
the CFMD model, where bone formation at four weeks following implantation was found to be greatest and most mature at the periphery and extended to various degrees deeper into the implantation site (Caralla et al., 2013; Luangphakdy et al., 2013; Takigami et al., 2007).

The explanation for this finding is uncertain. One possible explanation is that the localization of the TCP-HA granules in the center of the defect site resulted in an overestimation of bone formation due to the presence of residual ceramic. However, this does not appear to be the case. The finding of increased bone formation in the center of the defect persisted even after digital subtraction of the residual TCP-HA granules from the microCT images. Moreover, histological assessment of the samples confirmed that bone formation was denser in the center of the defect, in and around the region where the TCP-HA granules were implanted. These findings suggest the possibility of a direct effect of the TCP-HA granules in enhancing the osteoconductive environment in the center of the defect site above that provided by the ACS sponge alone. These findings may also suggest a possible interaction between the TCP-HA granules and the local efficacy of rhBMP-2. The rate of local delivery of BMP-2 and the long term retention of BMP-2 have been considered as key elements in optimizing BMP-2 dose and effects. Local retention of rhBMP-2 is characterized by an initial burst release of the implanted dose as soluble protein. This is followed by gradual loss of the protein from the site of implantation over a period of days to weeks. The local retention may be impacted by variables associated with site of implantation, the species, and the carrier in which it is implanted. In a rat ectopic model, using radiolabeled BMP-2, Friess and colleagues (Uludag et al., 2001) reported an initial burst of $30-40 \%$ of BMP-2 implanted using ACS carrier in the first several hours. Less than $10 \%$ of initial radioactivity was present beyond 10 days. In a rat femoral onlay model, the mean residence time of labeled rhBMP-2 was $7.8 \mathrm{~d}$ with less than $10 \%$ remaining at 3 weeks (FDA Approval Application P00054).

A unique interaction between BMP-2 and HA containing ceramic surfaces has long been recognized. BMP-2 binding to HA affinity columns has long been used in BMP purification and use of HA ceramic as a component in BMP-2 delivery was explored in a series of studies over a decade ago. These studies recognized that even if levels of long term binding may be low (likely less than $2 \%$ of the initial dose), the initial dose of BMP-2 is massively supraphysiological. Long term retention of even small amounts of BMP-2 on the surface of the ceramic material may be sufficient to induce prolonged and clinically useful local bone formation in vivo.

Winn et al. (1999) evaluated BMP-2 release from HA implants in rats, and found an early burst release followed by what appeared to be irreversible binding to HA. Alam et al. (2001) evaluated various ratios of hydroxyapatite to tricalciumphosphate as carriers for BMP-2, and found greater bone formation with a high HA ratio.

Louis-Ugbo et al. (2002) similarly examined release from a ceramic carrier using a rabbit posterolateral fusion model. Using biphasic (HA/TCP) calcium phosphate (BCP) the ceramic alone was compared to a $\mathrm{BCP} /$ collagen composite. Local retention at $3 \mathrm{~h}$ was $97 \%$ and $86 \%$ for $\mathrm{BCP} /$ collagen and $\mathrm{BCP}$, respectively. Radioactivity was detectable throughout the study with $<5 \%$ remaining at 5 weeks.

Given the known affinity between rhBMP-2 and HA and other ceramics, it is possible that the presence of the TCP-HA ceramic in the center of the defect may have served as a site of local binding for rhBMP-2 that was delivered into the site, reducing the rhBMP-2 diffusion rate from the site and prolonging the residence time of rhBMP-2 or presenting rhBMP-2 in a configuration that was more bioactive. Prolonged residence time of rhBMP-2 in the defect site has been associated with an increase in bone formation in several prior studies (Bouxsein et al., 2001; Schmoekel et al., 2004). Enhanced local bone formation around TCP-HA could also simply represent an enhanced osteoconductive environment of TCP-HA, relative to ACS. In this context, we note that comparing the retention profile of rhBMP-2/ACS to rhBMP-2/ACS in combination with TCP-HA in a radiolabeled rabbit posterolateral arthrodesis model was unable to show differences in retention kinetics when TCP-HA was added (Medtronic Internal Report, NC11023). Both test groups retained ${ }^{125} \mathrm{I}-\mathrm{rhBMP}-2$ at the site of administration in a similar manner for the 5 week duration of the study. Therefore, at this point, an explanation for the finding of enhanced bone formation associated in regions where TCP-HA was present is uncertain, and will need to be explored in subsequent in vitro and in vivo studies.

\section{Conclusion}

This study did not support the hypothesis that the addition of unprocessed bone marrow aspirate clot will improve the rate and effectiveness of bone regeneration in a site engrafted with rhBMP-2/ACS/TCP-HA+BMA, using a technique that involved rolling both TCP-HA granules and bone marrow clot into the center of a collagen sponge construct in which rhBMP-2 was adsorbed. All sites demonstrated bone formation and remodeling without acute inflammation and with rare cyst formation. Quantitative histomorphometry provided estimated percent bone area metrics which were very close to the $\% \mathrm{BV}$ data provided by microCT.

In contrast to prior studies using this model, the distribution of bone was greater at the center of defect than at the periphery of the defect, even after correction for unresorbed TCP-HA. This finding suggests a potential synergy between rhBMP-2 and the centrally placed ceramic and cellular components of the graft construct. Further optimization of rhBMP-2 performance may be achieved by investigation of more uniform distribution of TCP-HA granules within the construct, and alternative cell sourcing and delivery strategies in which cells are not embedded too deeply within the construct, improving the likelihood of their survival. 


\section{Acknowledgments}

This work was supported by Medtronic Spinal and Biologics Division (Memphis, TN). The authors gratefully acknowledge Cynthia Boehm, Tess Henderson, Brandon, Lampe, Amit Vasanji, Richard Rozic, Theresa Hefferan, James Herrick, Thomas Patterson for technical assistance, and Esteban Walker, $\mathrm{PhD}$ for assistance with statistical analysis. We wish to confirm that there are no known conflicts of interest associated with this publication and there has been no significant financial support for this work that could have influenced its outcome.

\section{References}

Alam MI, Asahina I, Ohmamiuda K, Takahashi K, Yokota S, Enomoto S (2001) Evaluation of ceramics composed of different hydroxyapatite to tricalcium phosphate ratios as carriers for rhBMP-2. Biomaterials 22: 1643-1651.

Bae JH, Song HR, Kim HJ, Lim HC, Park JH, Liu Y, Teoh SH (2011) Discontinuous release of bone morphogenetic protein-2 loaded within interconnected pores of honeycomblike polycaprolactone scaffold promotes bone healing in a large bone defect of rabbit ulna. Tissue Eng Part A 17: 2389-2397.

Boden SD, Zdeblick TA, Sandhu HS, Heim SE (2000) The use of rhBMP-2 in interbody fusion cages. Definitive evidence of osteoinduction in humans: a preliminary report. Spine 25: 376-381.

Bouxsein ML, Turek TJ, Blake CA, D'Augusta D, Li X, Stevens M, Seeherman HJ, Wozney JM (2001) Recombinant human bone morphogenetic protein-2 accelerates healing in a rabbit ulnar osteotomy model. J Bone Joint Surg Am 83: 1219-1230.

Boyne PJ, Lilly LC, Marx RE, Moy PK, Nevins M, Spagnoli DB, Triplett RG (2005) De novo bone induction by recombinant human bone morphogenetic protein-2 (rhBMP-2) in maxillary sinus floor augmentation. J Oral Maxillofac Surg 63: 1693-1707.

Burkus JK, Gornet MF, Dickman CA, Zdeblick TA (2002) Anterior lumbar interbody fusion using rhbmp-2 with tapered interbody cages. J Spinal Disord Tech 15: 337-349.

Caralla T, Joshi P, Fleury S, Luangphakdy V, Shinohara K, Pan H, Boehm C, Vasanji A, Hefferan TE, Walker E, Yaszemski M, Hascall V, Zborowski M, Muschler GF (2013) In vivo transplantation of autogenous marrowderived cells following rapid intraoperative magnetic separation based on hyaluronan to augment bone regeneration. Tissue Eng Part A 19: 125-134.

Cipitria A, Reichert JC, Epari DR, Saifzadeh S, Berner A, Schell H, Mehta M, Schuetz MA, Duda GN, Hutmacher DW (2013) Polycaprolactone scaffold and reduced rhBMP-7 dose for the regeneration of critical-sized defects in sheep tibiae. Biomaterials 34: 9960-9968.

Connolly J, Guse R, Lippiello L, Dehne R (1989) Development of an osteogenic bone-marrow preparation. J Bone Joint Surg Am 71: 684-691.
Connolly JF, Guse R, Tiedeman J, Dehne R (1991) Autologous marrow injection as a substitute for operative grafting of tibial nonunions. Clin Orthop 266: 259-270.

Dawson E, Bae HW, Burkus JK, Stambough JL, Glassman SD (2009) Recombinant human bone morphogenetic protein-2 on an absorbable collagen sponge with an osteoconductive bulking agent in posterolateral arthrodesis with instrumentation. A prospective randomized trial. J Bone Joint Surg Am 91: 1604-1613.

Fiorellini JP, Howell TH, Cochran D, Malmquist J, Lilly LC, Spagnoli D, Toljanic J, Jones A, Nevins M (2005) Randomized study evaluating recombinant human bone morphogenetic protein-2 for extraction socket augmentation. J Periodontol 76: 605-613.

Govender S, Csimma C, Genant HK, Valentin-Opran A, Amit Y, Arbel R, Aro H, Atar D, Bishay M, Borner MG, Chiron P, Choong P, Cinats J, Courtenay B, Feibel R, Geulette B, Gravel C, Haas N, Raschke M, Hammacher E, van der Velde D, Hardy P, Holt M, Josten C, Ketterl RL, Lindeque B, Lob G, Mathevon H, McCoy G, Marsh D, Miller R, Munting E, Oevre S, Nordsletten L, Patel A, Pohl A, Rennie W, Reynders P, Rommens PM, Rondia J, Rossouw WC, Daneel PJ, Ruff S, Ruter A, Santavirta S, Schildhauer TA, Gekle C, Schnettler R, Segal D, Seiler H, Snowdowne RB, Stapert J, Taglang G, Verdonk R, Vogels L, Weckbach A, Wentzensen A, Wisniewski T (2002) Recombinant human bone morphogenetic protein-2 for treatment of open tibial fractures: a prospective, controlled, randomized study of four hundred and fifty patients. J Bone Joint Surg Am 84: 2123-2134.

Hernigou P, Poignard A, Beaujean F, Rouard H (2005a) Percutaneous autologous bone-marrow grafting for nonunions. Influence of the number and concentration of progenitor cells. J Bone Joint Surg Am 87: 1430-1437.

Hernigou P, Poignard A, Manicom O, Mathieu G, Rouard H (2005b) The use of percutaneous autologous bone marrow transplantation in nonunion and avascular necrosis of bone. J Bone Joint Surg Br 87: 896-902.

Hernigou P, Mathieu G, Poignard A, Manicom O, Beaujean F, Rouard H (2006) Percutaneous autologous bone-marrow grafting for nonunions. Surgical technique. J Bone Joint Surg Am 88 Suppl 1: 322-327.

Huang W, Carlsen B, Wulur I, Rudkin G, Ishida K, Wu B, Yamaguchi DT, Miller TA (2004) BMP-2 exerts differential effects on differentiation of rabbit bone marrow stromal cells grown in two-dimensional and three-dimensional systems and is required for in vitro bone formation in a PLGA scaffold. Exp Cell Res 299: 325-334.

Jones CB, Sabatino CT, Badura JM, Sietsema DL, Marotta JS (2008) Improved healing efficacy in canine ulnar segmental defects with increasing recombinant human bone morphogenetic protein-2/allograft ratios. J Orthop Trauma 22: 550-559.

Kempen DH, Lu L, Hefferan TE, Creemers LB, Maran A, Classic KL, Dhert WJ, Yaszemski MJ (2008) Retention of in vitro and in vivo BMP-2 bioactivities in sustained delivery vehicles for bone tissue engineering. Biomaterials 29: 3245-3252.

Kim HD, Valentini RF (2002) Retention and activity of BMP-2 in hyaluronic acid-based scaffolds in vitro. $\mathrm{J}$ Biomed Mater Res 59: 573-584. 
Kinsella CR, Jr., Bykowski MR, Lin AY, Cray JJ, Durham EL, Smith DM, DeCesare GE, Mooney MP, Cooper GM, Losee JE (2011) BMP-2-mediated regeneration of large-scale cranial defects in the canine: an examination of different carriers. Plast Reconstr Surg 127: $1865-1873$.

Louis-Ugbo J, Kim HS, Boden SD, Mayr MT, Li RC, Seeherman H, D'Augusta D, Blake C, Jiao A, Peckham S (2002) Retention of 125I-labeled recombinant human bone morphogenetic protein- 2 by biphasic calcium phosphate or a composite sponge in a rabbit posterolateral spine arthrodesis model. J Orthop Res 20: 1050-1059.

Luangphakdy V, Walker E, Shinohara K, Pan H, Hefferan T, Bauer TW, Stockdale L, Saini S, Dadsetan M, Runge MB, Vasanji A, Griffith L, Yaszemski M, Muschler GF (2013) Evaluation of osteoconductive scaffolds in the canine femoral multi-defect model. Tissue Eng Part A 19: 634-648.

Majors AK, Boehm CA, Nitto H, Midura RJ, Muschler GF (1997) Characterization of human bone marrow stromal cells with respect to osteoblastic differentiation. J Orthop Res 15: 546-557.

Muschler GF, Huber B, Ullman T, Barth R, Easley K, Otis JO, Lane JM (1993) Evaluation of bone-grafting materials in a new canine segmental spinal fusion model. J Orthop Res 11: 514-524.

Muschler GF, Boehm C, Easley K (1997) Aspiration to obtain osteoblast progenitor cells from human bone marrow: the influence of aspiration volume. J Bone Joint Surg Am 79: 1699-1709.

Muschler GF, Nakamoto C, Griffith LG (2004) Engineering principles of clinical cell-based tissue engineering. J Bone Joint Surg Am 86: 1541-1558.

Muschler G, Raut VP, Patterson T, Wenke JC, Hollinger JO (2010) The design and use of animal models for translational research in bone tissue engineering and regenerative medicine. Tissue Eng Part B Rev 16: 123-145.

Schmoekel H, Schense JC, Weber FE, Gratz KW, Gnagi D, Muller R, Hubbell JA (2004) Bone healing in the rat and dog with nonglycosylated BMP-2 demonstrating low solubility in fibrin matrices. J Orthop Res 22: 376-381.

Suh DY, Boden SD, Louis-Ugbo J, Mayr M, Murakami H, Kim HS, Minamide A, Hutton WC (2002) Delivery of recombinant human bone morphogenetic protein-2 using a compression-resistant matrix in posterolateral spine fusion in the rabbit and in the non-human primate. Spine 27: $353-360$.

Takigami H, Kumagai K, Latson L, Togawa D, Bauer T, Powell K, Butler RS, Muschler GF (2007) Bone formation following OP-1 implantation is improved by addition of autogenous bone marrow cells in a canine femur defect model. J Orthop Res 25: 1333-1342.

Tarkin IS, Siska PA, Zelle BA (2010) Soft tissue and biomechanical challenges encountered with the management of distal tibia nonunions. Orthop Clin North Am 41: 119-126.

Thomopoulos S, Kim HM, Silva MJ, Ntouvali E, Manning CN, Potter R, Seeherman H, Gelberman RH (2012) Effect of bone morphogenetic protein 2 on tendonto-bone healing in a canine flexor tendon model. J Orthop Res 30: 1702-1709.
Tiedeman JJ, Connolly JF, Strates BS, Lippiello L (1991) Treatment of nonunion by percutaneous injection of bone marrow and demineralized bone matrix. An experimental study in dogs. Clin Orthop 268: 294-302.

Uludag H, Gao T, Porter TJ, Friess W, Wozney JM (2001) Delivery systems for BMPs: factors contributing to protein retention at an application site. J Bone Joint Surg Am 83 Suppl 1: S128-135.

Winn SR, Uludag H, Hollinger JO (1999) Carrier systems for bone morphogenetic proteins. Clin Orthop Relat Res 367 Suppl: S95-106.

Yasko AW, Lane JM, Fellinger EJ, Rosen V, Wozney JM, Wang EA (1992) The healing of segmental bone defects, induced by recombinant human bone morphogenetic protein (rhBMP-2). A radiographic, histological, and biomechanical study in rats. J Bone Joint Surg Am 74: 659-670.

Yilgor P, Sousa RA, Reis RL, Hasirci N, Hasirci V (2010) Effect of scaffold architecture and BMP-2/BMP-7 delivery on in vitro bone regeneration. J Mater Sci Mater Med 21: 2999-3008.

Yong MR, Saifzadeh S, Askin GN, Labrom RD, Hutmacher DW, Adam CJ (2014) Establishment and characterization of an open mini-thoracotomy surgical approach to an ovine thoracic spine fusion model. Tissue Eng Part C Methods 20: 19-27.

\section{Other References}

FDA Approval Application P00054, April 30, 2004. Summary of safety and effectiveness data for Infuse bone graft. http://www.accessdata.fda.gov/cdrh_docs/pdf/ P000054b.pdf.

Medtronic Internal Report NC-11023. Effect of bulking agents on retention of 125 I-labeled recombinant human bone morphogenetic protein- 2 by the absorbable collagen sponge in the rabbit posterolateral arthrodesis model.

\section{Discussion with Reviewers}

Reviewer I: Why was only a 4 week time period was chosen for this study? Since a canine model was used, it seems a longer healing period would have been more appropriate in order to better appreciate the effects on bone repair from using the composite graft material composed of rhBMP-2, collagen, TCP/HA with clotted bone marrow or clotted wound blood. Please comment.

Authors: This is another point that is addressed more extensively in our prior publications. In brief, the CFMD model was designed as a biologically relevant screening model to assess the relative efficacy of variables of scaffold composition and design, drug delivery, and cell delivery. It has been very effective in this capacity to date. However, the CFMD model is not a critical sized defect, and if allowed to fill with blood and marrow from the local wound site, the defect would be expected to fill in and reform a cortex and intramedullary canal. We chose the 4 week time point because we recognized that there are two aspects of efficacy that are desirable in a clinical strategy: 1) rapid bone 
formation, and 2) rapid transition to effective remodeling. The 4 week time point allows us both to identify differences between materials with respect to early bone formation and to measure differences between materials with respect to remodeling. Screening tools are most effective if they are rapid and less expensive with respect to time and also limit the number of animals required to detect meaningful differences. By picking a model with a four-week readout and also a large animal model that provides 1 data point per animal allows comparison between materials within the same animal, controlling for the variation known to exist between animals. Through the combination of these attributes, the CFMD model has also proven to be rapid and statistically powerful, while also reducing the number of animals needed when compare to more traditional large segmental defects. 